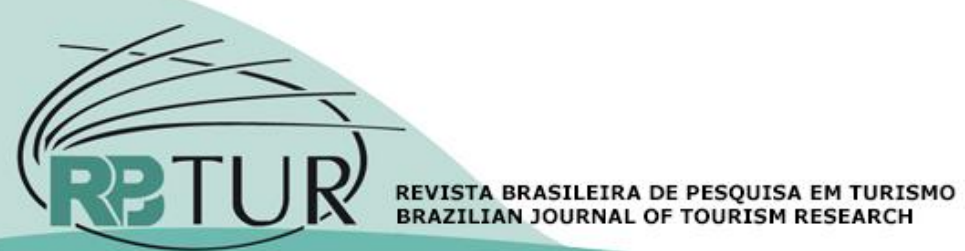

\title{
Artigos
}

\section{Turismo e fotografia: um estudo bibliométrico sobre o uso de metodologias de análise da imagem nas pesquisas em turismo}

\author{
Tourism and photography: a bibliometric study on using image analysis \\ methodologies in the tourism researches
}

\section{Turismo y fotografía: un estudio bibliometico sobre el uso de metodologías de análisis de la imagen en las investigaciones en turismo}

\author{
Karla Estelita Godoy'; lasmim da Silva Leite ${ }^{1}$ \\ 1 Universidade Federal Fluminense (UFF), Rio de Janeiro, Rio de Janeiro, Brasil.
}

Palavras-chave:

Pesquisa em turismo;

Metodologias de análise da imagem;

Novas metodologias;

Fotografia.
Keywords:

Tourism research;

Image analysis methodologies;

New methodologies;

Photography.

\section{Resumo}

Este artigo se propõe a investigar o uso de metodologias de análise da imagem em pesquisas de turismo nacionais e internacionais recentes (2012 a 2017). Por meio de pesquisa exploratória e de uma revisão sistemática de literatura, de caráter bibliométrico, em bases de periódicos mundiais, buscou-se verificar as principais metodologias utilizadas no campo do turismo, em quais áreas esses métodos são mais empregados e de que modo são coletadas imagens fotográficas para as pesquisas. Como resultado, verificou-se que as pesquisas em turismo utilizam, para analisar imagens, metodologias tradicionais como semiótica e análise de conteúdo. Diversas metodologias apareceram mais sutilmente, como é o caso da volunteer-employed photography, da antropologia visual/fotoetnografia, da foto elicitação, da Zaltman metaphor elicitation technique (ZMET), e outras, entre as quais a iconografia. Cabe salientar que o uso dessas metodologias nas pesquisas analisadas foi combinado com outros métodos qualitativos conceituados - entrevistas em profundidade e observação participante, por exemplo -, como forma de validar resultados da pesquisa. Contudo, notouse, por meio desse mapeamento, que as metodologias de análise visuais podem contribuir para a pesquisa em turismo, capturando o olhar do turista e oferecendo perspectivas que surveys ou entrevistas em profundidade não são capazes de fornecer. Assim, este artigo aponta novas possibilidades para as pesquisas em turismo.

Abstract

This article intends to investigate on using image analysis methodologies in recent national and international tourism surveys, from 2012 to 2017 . Through exploratory and bibliometric research on the basis of world-wide journals, we sought to verify the main methodologies used in the field of tourism, in which areas these methods are most often used and how images are collected for research. As a result, it was verified that tourism research uses traditional methodologies to analyze images, such as semiotics and content analysis. Several methodologies have appeared more subtly, such as volunteer-employed photography, visual anthropology / photo- nography, photo elicitation, Zaltman metaphor elicitation technique (ZMET), and others, including iconography. It should be noted that the use of these 
Palavras clave:

Investigación en turismo; Metodologías de análisis de la imagen;

Nuevas metodologias;

Fotografía.

Revisado por pares.

Recebido em: 19/11/2018.

Aprovado em: 28/05/2019. methodologies, in general in the area of management and marketing of tourist destinations, was based on other well-known qualitative methods - in-depth interviews and participant observation, for example - as a way of validating the results of the research. However, it was noted through this mapping that visual analysis methodologies can contribute to tourism research, capturing the tourist's gaze and offering perspectives that surveys or in-depth interviews are not able to provide. Thus, this article points out new possibilities for researches in tourism.

\section{Resumen}

Este artículo se propuso investigar el uso de metodologías de análisis de la imagen en investigaciones de turismo nacionales e internacionales recientes, entre los años de 2012 y 2017. Por medio de investigación exploratoria y bibliometrico en bases de periódicos mundiales se buscó verificar las principales metodologías que se utilizan en el campo del turismo, en qué áreas estos métodos son más empleados y de qué modo se recogen las imágenes para la investigación. Como resultado se verificó que las investigaciones en turismo utilizan metodologías tradicionales para analizar imágenes, tales como: semiótica y análisis de contenido. Diversas metodologías aparecieron más sutilmente, como es el caso de la volunteer-employed photography, de la antropología visual/fotoetnografía, de la foto elicitación, de la técnica Zaltman metaphor elicitación (ZMET), y otras, entre las cuales la iconografía. Cabe señalar que el uso de esas metodologías, en general en el área de gestión y marketing de destinos turísticos, se apoyó en otros métodos cualitativos conceptuados entrevistas en profundidad y observación participante, por ejemplo - como forma de validar los resultados de la investigación. Sin embargo, se notó por medio de ese mapeo que las metodologías de análisis visuales pueden contribuir a la investigación en turismo, capturando la mirada del turista y ofreciendo perspectivas que encuestas o entrevistas en profundidad no son capaces de suministrar. Así, este artículo apunta nuevas posibilidades para las investigaciones en turismo.

Como citar: Godoy, K.E.; Leite, I.S. (2019). Turismo e fotografia: um estudo bibliométrico sobre o uso de metodologias de análise da imagem nas pesquisas em turismo. Revista Brasileira de Pesquisa em Turismo, São Paulo, 13 (3), p. 71-91, set./dez. http://dx.doi.org/10.7784/rbtur.v13i3.1573

\section{INTRODUÇÃO}

O olhar do turista produz imagens e imaginários que, por sua vez, vão compor o complexo fenômeno turístico. No contexto contemporâneo, as fotografias estão cada vez mais presentes no dia a dia das pessoas, despertando desejos e necessidades e estimulando-as a conhecer destinos e culturas. Para além de ferramenta do marketing, a fotografia no turismo pode se constituir como modo de eternizar e compartilhar experiências - especialmente nas redes sociais em que a disseminação da informação é instantânea - e mesmo como forma de distinção, principalmente quando as viagens turísticas ganham dimensão de status social. As fotografias, quando registros desses deslocamentos, são via de comunicação direta dessas intencionalidades, bem como estarão abertas a interpretações e produção de sentidos.

Ao se constituírem como instrumentos de comunicação, as imagens conduzem à ampliação do conhecimento (Joly, 2012). Nesse sentido, entendendo-as em seu papel na construção de narrativas visuais (Gastal, 2005), estudar em profundidade as imagens fotográficas geradas para e pelo turismo acarretará contribuições teóricas e metodológicas para esse campo de investigação científica, pois, como salienta Susan Sontag (2004, p. 13), a foto torna a imagem “objeto, leve, de produção barata, fácil de transportar, de acumular, de armazenar".

No turismo, é frequente o uso de metodologias convencionais, algumas delas já bastante sedimentadas no espectro das pesquisas sobre os mais variados assuntos relacionados ao campo (Matteucci, 2013). Surveys, grupos focais e até pesquisas de base etnográfica vêm sendo cada vez mais empregadas como métodos. No entanto, pesquisadores afirmam que a área não se arrisca a inovar e utilizar novas metodologias, como situa Camargo (2008), a respeito dos estudos sobre a hospitalidade. Para o autor, estudos calcados em semiótica poderiam vir a ser um dos caminhos para se analisar esse campo de modo diferente, e, com isso, novos e outros saberes seriam vislumbrados. 
Nesse contexto, o objetivo deste estudo ${ }^{1}$, que integra análises e projetos considerados de caráter inovador desenvolvidos em nosso grupo de pesquisa Turismo, Cultura e Sociedade - UFF, foi realizar uma revisão sistemática de literatura a respeito da evolução nos últimos cinco anos da aplicação das metodologias de análises visuais em pesquisas empíricas na área de turismo que utilizam a fotografia como dado a ser analisado. Buscou-se ainda verificar em quais áreas do turismo essas metodologias têm sido mais aplicadas e quais são suas variações.

Pretende-se, assim, apresentar um panorama do uso das metodologias visuais em pesquisas nacionais e internacionais de turismo, no período que compreende os anos de 2012 a 2017. Realizou-se uma revisão sistemática de literatura, em bases de dados nacionais e internacionais, em que foi possível consultar diversos periódicos, dentre os quais destacam-se Annals of Tourism Research, International Journal of Tourism Research and Hospitality, Tourism Management, Asia Pacific Journal of Tourism Research, Journal of Travel Research, Marketing \& Tourism Review, Estudios y Perspectivas en Turismo, Revista Brasileira de Pesquisa em Turismo, Turismo e Análise e Caderno Virtual de Turismo.

\section{REVISÃO DE LITERATURA}

A fim de compreender o uso das metodologias de análise visuais, é fundamental que se conceituem e discutam os vários modos de se definir imagem.

De acordo com Joly (2012, p.38), que opera no campo da representação, uma imagem "material ou imaterial, visual ou não, natural ou fabricada [...] é antes de mais nada algo que se assemelha a outra coisa". $\mathrm{E}$, nesse aspecto, as palavras imagem e imaginário encontram seu ponto de convergência, pois tanto uma imagem concreta como uma imagem mental (imaginário) são construídas com base em uma referência.

O termo imagem não se restringe a fotografias ou pinturas - embora o enfoque deste estudo seja justamente imagens fotográficas. Em movimento ou estáticas, as imagens podem estar em filmes, desenhos, sonhos... Imagens, segundo Joly (2012), são representações do real, e pode-se chamar de "imagem" qualquer elemento visual que estabeleça uma narrativa (Gastal, 2005). Esses contos visuais estabelecem comunicação por meio de suas cores, signos, símbolos e texturas.

Se a imagem é, por tal definição, algo que se assemelha a outra coisa, logo nunca será a coisa em si.

\footnotetext{
Se ela parece é porque ela não é a própria coisa: sua função é, portanto, evocar, querer dizer outra coisa que não ela própria, utilizando o processo da semelhança; se a imagem é percebida como representação, isso quer dizer que a imagem é percebida como signo (Joly, 2012, p. 39).
}

Já para Bergesio, Montial e Scalone (2012), o conceito se amplia. A imagem é construída segundo determinada realidade, logo essa representação consiste em uma reconstrução.

No bojo da discussão a respeito do conceito de imagem, que envolve outras diversas áreas do conhecimento e interpretações, situa-se a fotografia, como um tipo de imagem que vem sendo produzida a todo instante no mundo contemporâneo, principalmente em função do advento de smartphones, câmeras descartáveis ou portáteis. Em certa medida, todos podem ser fotógrafos. A fotografia capta e eterniza momentos, funcionando como suporte de memória capaz de representá-los (ou "re-apresentá-los", torná-los presentes outra vez).

A fotografia, segundo Sontag (2004), é capaz de produzir testemunhos incontestes de acontecimentos passados, embora possa distorcer elementos, pois apresenta certas limitações. Ainda de acordo com a teoria da autora, observa-se que apesar das distorções - em função também das múltiplas possibilidades de interpretação e codificação humana -, a foto é, portanto, a prova "de que algo existe ou existiu, e era semelhante ao que está na imagem" (Sontag, 2004, p. 14). Para Roland Barthes (1984), a fotografia transforma o sujeito em objeto, ultrapassando, assim, a existência, e eternizando momentos e indivíduos.

\footnotetext{
10 presente artigo científico obteve apoio financeiro da FAPERJ, visando à sua publicação. Também é fruto de pesquisas do L'Image (Laboratório de Metodologias de Análise da Imagem, coordenado pela Prof ${ }^{\mathrm{a}} \mathrm{Dr}^{\mathrm{a}}$ Karla Estelita Godoy), que conta com o fomento do CNPq.
} 
O pensamento de Salvagni e Silveira (2013) corrobora com a teoria de Sontag (2004), assim, a fotografia é considerada um registro simbólico, recorte de acontecimentos da sociedade. Nesse sentido, os autores acreditam que ela constitua valioso instrumento para a pesquisa científica. A fotografia, como um dispositivo, pode se somar a outros métodos de pesquisa, ajudando a (re)construir narrativas e permitindo a produção de análises, provocadas por meio do discurso imagético que carregam. Além disso, Salvagni e Silveira (2013) afirmam que o uso da fotografia em pesquisas científicas - quer seja por meio da produção de imagens por parte do pesquisador ou da análise da imagem produzida por outros - possibilita disseminação do conhecimento, na medida em que promove a interdisciplinaridade da pesquisa e o alcance de todos os públicos.

\begin{abstract}
[...] a fotografia usada como dispositivo de linguagem acadêmica cria a possibilidade de maior propagação dos estudos através do uso indiscriminado destas narrativas imagéticas. Isso quer dizer que a fotografia representa uma facilidade no sentido de fazer com que o trabalho acadêmico possa transitar não só nas outras áreas de conhecimento que não as ciências sociais, como também entre o publico leigo que venha a se interessar sobre o assunto (Salvagni \& Silveira, 2013, p. 2-3).
\end{abstract}

O uso da fotografia nas pesquisas científicas, em especial na área de Ciências Sociais, é uma tendência que segue a "cultura visual", já que na sociedade contemporânea os recursos visuais estão entre os elementos que intermedeiam as relações entre indivíduos. 0 hábito corriqueiro de produzir fotografias e fazer pequenos filmes está cada vez mais presente, mesmo que de modo amador.

De acordo com Edwards (2016, p. 166-167), “a própria natureza da fotografia enquanto traço mecânico e químico do corpo do sujeito que a tornou tão poderosa", isto é, além ser considerada um instrumento de poder para Sontag (2004), nota-se que a foto pode ser uma ferramenta útil para a pesquisa científica, possibilitando que o olhar do pesquisador "[...] relaxe, deseje e aproprie-se do sujeito" (p. 167) ou objeto pesquisado. Desse modo, a respeito da relação entre fotografia e pesquisa científica, Edwards (2016) sintetiza:

As fotografias sempre serão usadas, com grande efeito, como registros de campo, como lugares de interação social transcultural, como fontes para análises, como objetos de estudo e como sistemas visuais e sensoriais que levantam problemas [...] fundamentais (Edwards, 2016, p. 184).

O dispositivo fotográfico possibilita trazer o sujeito da pesquisa para o conteúdo do trabalho científico, por meio do empréstimo de sua imagem. Salvagni e Silveira (2013) enfatizam o caráter ético do uso dessa ferramenta. Autores como Diniz (2008) travam debate sobre os novos desafios éticos acerca do uso da imagem de um indivíduo, salientando a necessidade da devida autorização do pesquisado para a publicação de uma fotografia ou divulgação de um material audiovisual por meio da assinatura dos termos de consentimento livre e esclarecido que explicitam o caráter voluntário e não-remunerado da participação do sujeito da pesquisa. Deve-se levar em conta também o tipo de análise que é realizada a respeito de elementos como vestimenta, aparência e expressão (Salvagni \& Silveira, 2013).

Cabe ressaltar que, quando se trata do uso da fotografia em trabalhos acadêmicos, não se deve encarar essa imagem como mera ilustração ou objeto para justificar análises textuais. Para Rial (2014, p. 11), autora que estuda o campo da Antropologia Visual, "não se escreve apenas com palavras. As imagens também podem ser instrumentos poderosos na elaboração de textos [...], com grande capacidade de difusão de ideias".

A análise de uma imagem implica reflexões e interpretações que sejam propostas e que emerjam com base na própria imagem. De acordo com Martins (2016), autor que estuda a relação entre a Antropologia Visual e Turismo, é preciso tratar as imagens fotográficas de forma crítica. Assim, a fotografia deve suscitar narrativas a serem explicadas, por exemplo, segundo análise de elementos como enquadramento, uso de cores ou ausência delas, cortes, luz, elementos em cena, planos, entre outros. No entanto, a fotografia "dá a liberdade para que o leitor tenha as suas próprias percepções diante da imagem" (Salvagni \& Silveira, 2013, p. 6).

A fotografia propicia, inclusive, que posteriormente se observem nuances não percebidas facilmente pelo próprio pesquisador enquanto está em campo. Além disso, quando utilizada como objeto de análise em um 
texto científico, desencadeia diálogos "como uma janela capaz de refletir um ponto de vista da realidade" (Salvagni \& Silveira, 2013, p. 6).

Aplicando essas perspectivas de análise da imagem fotográfica ao turismo, pode-se afirmar que a fotografia oferece a esse campo de investigação inúmeras possibilidades, conforme indicam os resultados do presente estudo, relatados nas próximas sessões.

\title{
2.1 0 turismo na perspectiva da análise da imagem
}

A relação entre turismo e fotografia é forte e significativa. De acordo com Foster (2017), atravessa os séculos XIX e XX, passando a se integrar à experiência turística. Como ressalta a autora, a fotografia permite "a construção imagética do turismo" (Foster, 2017, p. 89), e é disseminada por meio de cartões postais e pela produção fotográfica do turista, sobretudo, em suas redes sociais.

Para Urry (2001, p. 187), a fotografia “dá forma à viagem”, enquanto para Pérez (2012) as imagens turísticas são vistas como práticas sociais que culminam na experimentação e na construção do olhar do próprio turista. Esse "olhar do turista" - termo cunhado por Urry (2001) - produz fotografias como forma de registrar tudo aquilo que é contemplado e gera possibilidades de ser eternizado.

\begin{abstract}
[...] As imagens fotográficas organizam nossas expectativas ou nossos devaneios sobre lugares que poderíamos contemplar. [...] Escolhemos parcialmente para onde ir, a fim de capturar imagens em um filme. A obtenção de imagens fotográficas organiza em parte nossas experiências enquanto turistas. Nossas recordações dos lugares onde estivemos são estruturadas em grande medida através das imagens fotográficas e do texto, sobretudo verbal, que tecemos em torno dessas imagens quando as mostramos para os outros. Assim, o olhar do turista envolve irredutivelmente a rápida circulação das imagens fotográficas (Urry, 2001, p.187).
\end{abstract}

Para Foster (2017), a fotografia e o turismo funcionam como um jogo, cujo objetivo é impulsionar e modificar discursos, rituais e organizações. As fotos, portanto, operam como um dispositivo criador de desejos, formador de valores que "orientam práticas, investem tempo e concentram economias, pois reúnem diversos processos heterogêneos" (Foster, 2017, p. 92). Nesse contexto, para autora, há um processo de massificação da fotografia criado por uma indústria que produz e estimula a utilização de produtos fotográficos de fácil acesso e manuseio, tornando-os econômicos e socialmente acessíveis a todo tipo de público.

Foster (2017) identifica a Eastman Kodak Company - empresa americana criada em 1888, pelo fundador George Eastman - como uma das mais representativas no ramo da fotografia. Segundo a autora, a Kodak, com o passar dos anos, modificou e revolucionou os modos de produção e tomada de fotografia, na medida em que criou "uma prática e um mercado para o fotógrafo amador com câmeras portáteis" (Foster, 2017, p. 92). Além disso, a Kodak implementa um conceito que designa a câmera como "companheira para todas as ocasiões" (p. 92), o que inclui as viagens. Desse modo, a Kodak procura

\footnotetext{
[...] evidenciar principalmente um turista em construção, circunscrito a práticas que o levam à fotografia [...]. Destaco a marcante intenção de atuação da empresa direcionada à figura do fotógrafo amador, com estratégias de enunciação e convencimento por meio de sua publicidade, dos manuais e de ações diversas como forma de educar sobre a fotografia (Foster, 2017, p. 92).
}

No entanto, Baumann, Lourenço e Lopes (2017), que também discutem a relação entre turismo e fotografia, apontam que o auge das fotografias de viagem se dá com o início da era digital, que alavancou o uso de câmeras digitais, aumentando, assim, as fotografias tiradas por turistas em viagens. Os smartphones com câmeras integradas também contribuíram, a posteriori, para a proliferação de fotografias turísticas na internet em sites de relacionamento, conhecidos como "redes sociais". Assim, "a quase omnipresença de smartphones faz com que o turista esteja, na sua generalidade, sempre pronto a fotografar" (Baumann, Lourenço \& Lopes, 2017, p.1413).

Nesse contexto, Siqueira, Manosso \& Massukado-Nakatani (2014) argumentam que as fotografias, em sua relação com o turismo, devem ser compreendidas para além de meros dispositivos para registros de 
memórias turísticas, mas sim como instrumentos poderosos que refletem modos de comunicação entre um destino turístico e os turistas.

Além de atuarem como transmissoras da imagem de um destino e seus elementos - paisagens naturais, patrimônios histórico-culturais, por exemplo -, as fotografias se convertem em "um processo cognitivo de absorção de informações, positivas ou não" (Siqueira, Manosso \& Massukado-Nakatani, 2014, p. 3). Nesse sentido, Azevedo (2017) aponta que conteúdos implícitos nas fotografias podem ser "deduzidos cognitivamente" e resultam em novos significados. Isto ocorre, porém, de acordo com o uso de metodologias de análise de imagem que possibilitam ao pesquisador em turismo realizar a leitura metodológica dos elementos que compõem a imagem.

Entretanto, de acordo com Mello (2015), são poucos os estudiosos que se debruçaram sobre o tema, que se propõem a estudar a fotografia como um modo de transcrição da realidade pelo turista. Balomenou e Garrod (2014) afirmam que as fotografias têm sido subutilizadas no turismo, quando não ignoradas. Entretanto, os autores argumentam que a lente da câmera fotográfica e o olho humano podem ser considerados um só e, portanto, representam a subjetividade do indivíduo. Nesse contexto, torna-se possível, por meio de uma fotografia, que o pesquisador compreenda o olhar e as intenções particulares do sujeito de sua pesquisa.

Mello (2015) destaca os principais autores que se dedicaram a pesquisar sobre esse tema: Urry (1997), Urry e Crashow (2001), Coghlan e Prideaux (2008), Donaire e Galí (2011), Thurlow e Jaworski (2011) e a própria Mello (2015). Nota-se, assim, que o estudo de fotografias turísticas ainda é um campo pouco explorado por metodologias de pesquisa.

Matteucci (2013) corrobora com o pensamento de pesquisadores internacionais ao defender que o uso de metodologias de análise da imagem pode colaborar para a resolução de "armadilhas" provocas pelas abordagens metodológicas convencionais. Nesse sentido, o autor afirma, assim como Mello (2015), que, embora as metodologias visuais sejam difundidas em áreas como a Antropologia e a Sociologia, no Turismo, o uso dessas metodologias "continua a ser marginal" (p. 191).

Por meio de uma revisão sistemática de literatura em periódicos nacionais e internacionais, verificou-se que, no período contemplado pela pesquisa (2012 a 2017), o ano de 2016 foi o mais representativo, no que tange a pesquisas empíricas que se utilizaram de metodologias visuais. Nesse ano, ainda, observa-se um volume de produção brasileira, especialmente de acadêmicos do sul do país, trabalhando a imagem fotográfica de destinos turísticos como Curitiba (PR) e Blumenau (SC). Cumpre destacar, nesse sentido, a produção de Manosso e Gândara (2016) e Moretti, Bertoli e Zucco (2016).

Produções em número considerável também foram publicadas nos anos de 2012, 2013 e 2015. Entretanto, diferentemente do que ocorreu em 2016, a maioria das publicações foi realizada por estrangeiros ou brasileiros em revistas internacionais. A taxa de publicação em revistas asiáticas nesse período também despertou atenção.

Os métodos de análise de imagem são pouco utilizados nas pesquisas sobre turismo no Brasil. Tal afirmação se justifica pelo retorno de pesquisas nacionais nas bases para esse estudo. Na base Publicações em Turismo foi encontrado apenas um periódico que tratava do assunto, e, nas demais bases, os artigos somam sete, todos concentrados em compreender a imagem do destino turístico com base em fotografias de turistas. Já no que diz respeito ao cenário internacional, o uso dessas metodologias aparentemente é mais difundido.

A respeito dos dados da pesquisa, no cenário internacional, Matteucci (2013) já sinalizava que as pesquisas que utilizam análise da imagem têm ganhado força nos últimos anos, dentro e fora do Turismo. De acordo com o autor, esse movimento de pesquisadores interessados em trabalhar com imagens foi reforçado pela edição de 2008 da revista Forum: Qualitative Social Research, volume dedicado somente às pesquisas que contemplassem metodologias visuais.

No entanto, Baumann, Lourenço e Lopes (2017) apontam em seu trabalho que as pesquisas que utilizam metodologias de análise da imagem no turismo, em especial a análise de conteúdo, estão normalmente restritas à "análise de brochuras, postais e websites" (p. 1414), e, portanto, quase sempre relacionadas aos 
campos de marketing e gestão de destinos turísticos. Este é o caso de um dos artigos recuperados nas buscas realizadas para esta pesquisa. Os autores Manosso, Bizinelli e Gândara (2013), realizaram pesquisa documental na rede social Flickr, com objetivo de identificar como a imagem de Curitiba (PR) era percebida pelos turistas que visitavam a cidade.

\subsection{Tendências metodológicas e possibilidades de uso das metodologias visuais}

As pesquisas que utilizam metodologias de análise de imagem, em geral, são predominantes nos campos da Linguística, Psicologia, Antropologia e do Marketing. São raros os livros de metodologia em turismo que apontam tais metodologias como possíveis caminhos para a pesquisa na área. Deve-se ponderar também o fato de o turismo ser uma área de estudo relativamente nova - por isso, aos poucos, começa a se lançar a novos caminhos teóricos e metodológicos, especialmente no que diz respeito às investigações de alcance nacional.

Como visto anteriormente, as pesquisas que congregam turismo e metodologias visuais ainda são incipientes, embora estimuladas por autores reconhecidos na área como possibilidades promissoras (Urry, 2001); (Camargo, 2008). No livro O olhar do turista, em que John Urry (2001) discute a construção do olhar do turista e das imagens fotográficas turísticas, já há indicações de possibilidades de análise com base nessas informações.

Nesse sentido, entendendo o turismo como fenômeno interdisciplinar, capaz de convergir com outras áreas, de modo a intercambiar métodos e conceitos, as metodologias de análise da imagem se apresentam como algo inovador, propondo diferentes técnicas para a aplicação nos estudos no campo do turismo. É o que defendemos em pesquisas e projetos desenvolvidos em nosso Grupo de Pesquisa, de que é parte o presente artigo, ajudando a fornecer conteúdos que fundamentem nossa argumentação.

Com base nos artigos recuperados em buscas nas bases de dados, observou-se a utilização de alguns métodos de análise da imagem. Entretanto, a seguir, tais métodos serão apresentados com referência a autores consolidados no campo da imagem e que, na maioria dos casos, estiveram presentes nos periódicos analisados.

Cabe ressaltar que serão descritas apenas as metodologias resultantes da busca nas bases de periódicos escolhidas, embora existam outras metodologias de análise da imagem, como, por exemplo, a Visual Narrative Art que se ocupa da leitura de imagens artísticas como meio de recontar acontecimentos históricos (Megehee \& Woodside, 2010). Contudo, o objetivo deste artigo é apresentar os métodos visuais de pesquisa mais utilizados nos últimos cinco anos.

\subsubsection{Análise de conteúdo}

A análise de conteúdo é uma metodologia que teve origem nos Estados Unidos e sua aplicação primária nas áreas de estudo das Ciências Sociais (Prasad, 2008). No entanto, embora a análise de conteúdo seja frequentemente confundida com a semiótica, sua natureza é quantitativa.

A análise de conteúdo concentra-se em descrever e desvendar quantitativamente os atributos contidos em uma imagem, o que possibilita identificar a frequência, a ocorrência e o agrupamento de elementos essenciais para a compreensão do que se pretende verificar em uma imagem. Assim, a análise de conteúdo está centrada em decodificar o número de atributos que uma imagem contempla (Stepchenkova \& Zhan, 2013).

Para analisar o conteúdo de uma fotografia, por exemplo, são elaboradas categorias como pessoas na foto, sexo, idade, cor da roupa etc. Além disso, de acordo com Stepchenkova e Zhan (2013), a análise de conteúdo pode levar em conta aspectos como "ângulo temporal" (período em que a fotografia foi produzida), "ângulo geográfico" (onde foi registrada) e "produção” (quem fotografou).

Stepchenkova e Zhan (2013) acreditam que a análise de conteúdo é mais fiel ao significado dos signos e contextos de uma fotografia que a semiótica. Para os autores, mesmo que a análise de conteúdo deixe escapar elementos de subjetividade nas fotos e não se configure como um método interpretativo, é 
considerada uma metodologia capaz de sistematizar, categorizar e resumir os atributos de uma foto, de modo que seja possível realizar comparações e inferências a respeito do tema de maneira quantitativa e categórica.

Nesse contexto, para que a análise de conteúdo fique mais completa, é possível combinar o método com a semiótica, tal como fizeram os autores Stepchenkova e Zhan (2013), em sua pesquisa sobre a imagem de um destino turístico, em que foram coletadas, para fins de análise, imagens fotográficas de sites oficiais do país (Peru), bem como de turistas pela rede social Flickr.

\subsubsection{Semiótica}

Por vezes chamada de "ciência dos signos", a semiótica (filosofia da linguagem) é uma disciplina que, embora tenha raízes que remontam à Antiguidade grega, pode ser considerada relativamente recente, pois surge como tal no início do século XX. Frequentemente confundida com a semiologia (estudo de linguagens particulares, para além das imagens), "seus grandes percursores são o linguista suíço Ferdinand Saussure, na Europa, e o cientista Charles Peirce, nos Estados Unidos" (Joly, 2012, p. 30).

Para Saussure (1974, como citado em Joly, 2012), a língua não pode ser considerada o único modo de comunicação, isto é, não se constitui como um "único sistema de signos que exprimem as ideias" (Joly, 2012, p. 31). Os signos devem ser compreendidos como elementos que geram significados. Assim, a textura de uma superfície pictórica, a ausência de cor em uma fotografia ou um objeto que se movimenta em um vídeo podem ser considerados signos, pois exprimem significados. Nesse sentido, entende-se que, embora a imagem seja visual, possui sua própria linguagem dotada de símbolos particulares e significados.

A imagem é a própria mensagem. Desse modo, a semiótica possibilita analisar imagens, sendo elas pinturas ou fotografias, sem amarras. 0 pesquisador não tem obrigação de se deter à intenção do produtor da imagem. Pelo contrário, a semiótica fornece o desprendimento para compreender o que a mensagem provoca de significações, pois acredita-se que nem o autor, produtor da imagem, domina toda a significação de sua produção (Joly, 2012).

No caso da fotografia, Ferrari e Gândara (2015, p. 115) sintetizam o estudo da semiótica afirmando que esta "[...] pretende apreender como se dá a construção dos sentidos do texto (verbal ou visual), e é a partir dela que se pode captar a complexidade e a potência da comunicação pela imagem da fotografia".

Assim, verificou-se que tal método busca analisar o significado que os signos produzem no processo de comunicação. E, para além de seus significados tradicionais, há múltiplas possibilidades de novos significados e interpretações. Não necessariamente o pesquisador deve interpretar a imagem com os mesmos olhos de quem a produziu. Essa é uma das principais diferenças entre a análise semiótica visual e a análise de textos, pois a dos signos imagéticos permite contemplar aspectos subjetivos e implícitos.

\subsubsection{Antropologia Visual}

A Antropologia Visual é uma das áreas da Antropologia Sociocultural e consiste no "estudo das significações de imagens singulares sobre a diversidade cultural, que transportam as representações sociais para os suportes fotográficos e filmográficos" (Campos, 1996, p. 280).

A Antropologia Social, por si só, torna o pesquisador um "antropólogo turista" (Martins, 2016, p. 529). 0 método utilizado nesse campo permite o conhecimento da "diversidade e da diferença cultural", que "sempre teve em si um princípio turistificador, traduzido nas ideias de viagem e de encontro com os outros, associado ao trabalho de campo e ao quesito metodológico-epistemológico da contextualização do que se estuda" (Martins, 2016, p. 529).

A relação entre a Antropologia Social e a Antropologia Visual se dá na medida em que a Antropologia, quando dedicada à análise e à produção de imagens, busca por meio de suportes imagéticos (fotográficos ou fílmicos) descrever e analisar aspectos de um grupo ou uma cultura. 
O estudo das visualidades no campo antropológico pode levar à compreensão dos espaços e das relações sociais. 0 que se analisa é o cunho narrativo que se imprime na produção de imagens, que podem ser produzidas pelo próprio pesquisador ou por outrem (Martins, 2016).

Para Campos (1996), a análise de imagens é um recurso importante para a Antropologia, pois, além de propiciar a análise de processos históricos em sociedades diversas, possibilita a criação de uma narrativa com base em um recorte fotográfico, com vistas à transmissão e à produção de conhecimentos. Para a autora, as imagens possibilitam comparar registros e analisar processos de construção de identidades étnicas, "mesmo que tais momentos tenham sido filtrados pelo olhar que domina a câmera" (Campos, 1996, p. 280), isto é, o do pesquisador.

No entanto, Martins (2016) salienta que fazer uma antropologia visual não consiste em apenas produzir fotografias, fazer vídeos e "[...] nem tampouco receber e ou tratar imagens disponíveis (produzidas por outros) de forma acrítica" (Martins, 2016, p. 536). É necessária uma análise profunda e crítica, pois essa metodologia de pesquisa ajuda a produzir "uma redefinição das relações de poder tradicionais entre pesquisador e os seus objectos/sujeitos [sic] de estudo, facilitando novas formas de participação e comunicação antropológica" (Martins, 2016, p. 536).

Para realizar uma pesquisa com base na Antropologia Visual, é preciso que o pesquisador domine a "especificidade da linguagem fotográfica" (Achutti, 1997, p. 37) e que o fotógrafo "tenha a base (ou substrato) do olhar do antropólogo, com suas interrogações e formas específicas de olhar o outro" (Achutti, 1997, p. 37).

Cabe destacar que o uso da Antropologia Visual como metodologia para estudos em turismo é pouco verificada. Contudo, em algumas pesquisas, tal como as que empreendemos em nossos projetos, pode-se observar que a aplicação do método desdobra diversos aspectos para a análise do objeto de estudo, descortina diferentes possibilidades de coleta de dados, torna mais harmônica e aproximada a entrada no campo e a relação com os sujeitos da pesquisa, e amplia o diálogo com textos acadêmicos/científicos de outras áreas do conhecimento.

\subsubsection{Fotoetnografia}

A fotoetnografia é uma das metodologias da Antropologia Visual. Esse termo foi cunhado pelo antropólogo brasileiro Achutti, em 1997. A metodologia prevê o registro de elementos culturais, por meio de fotografias sequenciais como forma de narrativas realizadas por antropólogos. E, diferentemente do que se dá com a semiótica, há intencionalidade ao se produzir as fotos, pois se pretende contar a história de uma comunidade, de uma localidade. A fotografia se propõe, então, a ser uma comunicação prolongada a respeito de pesquisas de cunho antropológico.

A fotoetnografia tem a principal função de comunicar e transmitir, por meio de mensagens visuais, narrativas de grupos sociais ou elementos culturais. Nas palavras de Achutti (1997, p. 14 como citado em Cavedon, 2005, p. 21), "no uso da fotografia como uma narrativa imagética [pode-se] preservar o dado e convergir para o leitor uma informação cultural a respeito do grupo estudado".

Nos periódicos analisados observou-se uma tendência à fotoetnografia. As fotografias não partem somente da câmera do antropólogo, mas também da comunidade ou dos turistas. Os pesquisadores combinaram a fotoetnografia ao método VEP (volunteer-employed photography), buscando construir narrativas com o olhar da própria comunidade, segundo fotografias próprias dos pesquisados.

Esse é o caso do periódico Using volunteer-employed photography to inform tourism planning decisions: a study of St David's Peninsula, Wales, de Balomenou e Garrod (2014), que utilizam a tríade formada por diários de fotografia, entrevistas quantitativas (para descobrir dados demográficos) e aplicação do VEP para que os próprios turistas possam produzir suas narrativas a respeito da península de St. David. Outros artigos utilizam combinação de métodos similares como o Crossed gazer over an old city photography and the experimentation of heritage place, de Santos (2016), que, para além da fotoetnografia, utiliza métodos da etnografia, como a entrevista em profundidade e também se vale da semiótica. 


\subsubsection{Volunteer-employed photography (VEP)}

No volunteer-employed photography (VEP), os entrevistados da pesquisa são os produtores das fotos. Em geral, são feitos alguns questionamentos ou pedidos para que criem uma narrativa com fotos produzidas por eles mesmos, e, então, quando a câmera Ihes é fornecida, criam-se dados para análise posterior.

Esse método foi explorado pela primeira vez em 1970 por Traweek, que entregou uma câmera a dois participantes especialistas no assunto da pesquisa em temáticas a respeito de um rio e pediu a eles que fotografassem suas experiências e percepções. 0 resultado da pesquisa obteve sucesso, e, de acordo com Balomenou e Garrod (2014), desde então mais de 300 estudos lançaram mão da técnica.

Embora também possa ser encarado como uma técnica de coleta de dados e não uma metodologia em si, o VEP contempla o caráter subjetivo, que, anteriormente, era considerado uma fraqueza em outras metodologias. Ele possibilita que os "próprios pesquisados" sejam protagonistas das suas histórias ao criarem narrativas, e cabe ao pesquisador interpretá-las. Costumam-se adotar, junto ao VEP, entrevistas em profundidade ou diários de fotografia, para que o pesquisador possa entender o processo de produção e o resultado das fotos, assim como realizado no estudo da península de St. David (Balomenou \& Garrod, 2014).

\subsubsection{Foto elicitação}

A metodologia de foto elicitação é similar à ZMET, pois visa extrair informações do participante por meio de fotografias. Entretanto, para esse método, o participante não precisa necessariamente ser o produtor da foto. Nessa metodologia, às fotografias são associadas imagens de destinos, pessoas ou atividades capazes de suscitar no participante sentimentos e recordações que forneçam ao pesquisador respostas para sua investigação.

Matteucci (2013) realizou uma revisão de literatura e constatou que há quatro modos principais de aplicação da foto elicitação que têm sido utilizados recorrentemente nas pesquisas de cunho social. Nesse sentido, as fotografias podem ser: produzidas pelo pesquisador, reunidas pelo pesquisador, produzidas pelo participante da pesquisa, ou recolhidas pelo participante da pesquisa.

As fotografias utilizadas nessa metodologia devem estar relacionadas com a experiência de algum momento da vida do participante para que ele possa comentar e refletir sobre o que lhe vem à memória. Recomendase o uso desse método para evocar informações e nuances antes omitidas.

No entanto, Cahyanto, Pennington-Gray e Thapa (2013) alertam para o fato de que, no caso de o participante ser o produtor das fotos e sair a campo para capturá-las, alguns fatores podem prejudicar a pesquisa, como a inabilidade de algumas pessoas com a câmera (obtendo imagens de má qualidade ou até mesmo diferentes das idealizadas) e a possibilidade de perdê-la ou danificá-la.

\subsubsection{Zaltman metaphor elicitation technique (ZMET)}

A Zaltman metaphor elicitation tecnique (ZMET) é uma técnica similar ao VEP, mas, nesse caso, a análise dos dados coletados é mais profunda, passando por etapas que envolvem o sujeito produtor da imagem. A ZMET é um método projetivo derivado da neurobiologia, da psicanálise e da psicologia, que consiste em dar aos participantes câmeras fotográficas e instruí-los a coletar imagens que respondam o problema de uma pesquisa.

Após a primeira etapa, em que os participantes da pesquisa coletam imagens com base em seus sentimentos e experiências relacionados ao objeto da investigação, os participantes são convidados a participar de uma entrevista em grupo, em que são incitados a contar histórias por trás das fotografias. Nesse momento, o pesquisador passa a fazer perguntas sobre como e por que a foto foi tirada, por qual motivo o participante escolheu determinado ângulo, entre outras questões.

O ZMET é um método que leva o pesquisador além das possibilidades do VEP ou da fotoetnografia, pois há um momento em que o participante pode contar a história por trás das fotografias registradas e fornecer informações a respeito do objeto de investigação, primordiais para a pesquisa científica. 
O uso de imagens como meio de coleta de dados do ZMET é baseado na premissa de que a comunicação humana é, sobretudo, não-verbal (Zaltman, 1997; Zaltman \& Higie, 1993). Pesquisas anteriores mostraram que apenas 30\% no máximo do significado em uma troca social é transmitido por palavras (Knapp, 1980; Mehrabian, 1971; Weiser, 1988). Zaltman, por outro lado, notou que as imagens contêm metáforas que podem ser visuais, verbais, matemáticas ou mesmo musicais (Zaltman, 1997). ZMET afirma que essas metáforas são fundamentais na tentativa de compreender a voz do entrevistado (Khoo-lattimore \& Prideaux, 2013, p. 1039). [tradução nossa]

Percebe-se, com isso, que o ZMET acredita que a comunicação transcende questões verbais. A utilização de fotografias como meio de coleta de dados para pesquisas científicas possibilita captar subjetividades que outros métodos mais rigorosos e fechados em si não são capazes.

\section{METODOLOGIA}

Esta pesquisa consiste em uma revisão sistemática da literatura, de caráter bibliométrico e natureza exploratória. Optou-se pelo uso deste método de pesquisa, pois, de acordo com Chueke e Amatucci (2015, p. 2), a revisão sistemática de literatura serve para “[...] mapear as origens dos conceitos existentes, apontar as principais lentes teóricas usadas para investigar um assunto e levantar as ferramentas metodológicas utilizadas em trabalhos anteriores".

A bibliometria, método elaborado por Pritchard no final da década de 1960, é definida como “[...] a aplicação de métodos estatísticos e matemáticos na análise de obras literárias" (Pritchard, 1969 citado por Chueke \& Amatucci, 2015, p. 2). Nesse sentido, de acordo com os autores, os objetivos do método são: mapear a produção de artigos de um campo do saber, bem como as comunidades acadêmicas, e identificar redes de pesquisadores influentes que se dedicam ao estudo do assunto pesquisado (Chueke \& Amatucci, 2015).

O método bibliométrico pode "[...] colaborar na tarefa de sistematizar as pesquisas realizadas num determinado campo de saber e endereçar problemas a serem investigados em pesquisa futuras" (Chueke \& Amatucci, 2015, p. 2). Assim, por meio desse trabalho, pretende-se indicar novas possibilidades metodológicas pouco exploradas para a pesquisa científica em turismo.

Para realização de um estudo bibliométrico é indicado que o pesquisador atenda às "Leis" que regem esse modelo de estudo, tais como: Lei de Lotka, em que se deve levantar o impacto da produção de um autor para a área de conhecimento em que a pesquisa se localiza; Lei de Bradford, em que se devem avaliar os periódicos mais relevantes que tratam do tema da pesquisa; e, por fim, a Lei de Zipf, que aponta a necessidade de avaliar os temas recorrentes relacionados ao assunto da pesquisa (Chueke \& Amatucci, 2015).

Em 1926, a Lei de Lotka (relação do quadrado inverso) foi criada com o objetivo de mapear produtividade científica, analisando a contribuição dos autores para um campo específico do conhecimento, em um recorte temporal. Entre 1965 e 1971, o teórico Price aperfeiçoou a teoria de Lotka, dando origem à proposição de que, em uma área do conhecimento, 1/3 dos trabalhos acadêmicos é produzido por menos de 1/10 dos autores mais produtivos do campo de estudo. Esse dado, quando aplicado, de acordo com Rodrigues e Viera (2016) apresenta uma média de 3,5 documentos por autor, enquanto $60 \%$ dos outros pesquisadores da área produzem apenas um único documento sobre o tema (Rodrigues \& Viera, 2016).

Assim, com base na Lei de Lotka, infere-se que há muitos autores publicando apenas um artigo sobre um campo do saber, deixando de esgotar a temática da pesquisa, enquanto $40 \%$ dos pesquisadores produzem mais de 3 trabalhos sobre um tema de pesquisa. Percebe-se também, de acordo com a relação do quadrado inverso, que, à medida que o campo do saber se consolida e as publicações aumentam, os autores que produzem muitos trabalhos se tornam menos frequentes.

A Lei de Bradford foi criada em 1934 e aponta que muitos periódicos produzem poucos artigos relevantes a uma temática em um campo do saber, ao passo que, poucos periódicos produzem muitos artigos "supostamente de maior qualidade ou relevância" (Rodrigues \& Vieira, 2016, p. 170) para uma área do conhecimento. De acordo com essa Lei, se "[...] uma grande coleção de periódicos for disposta em ordem decrescente de produtividade de artigos de um determinado assunto, pode-se identificar um cluster central de títulos que tratam essencialmente dessa temática" (Rodrigues \& Vieira, 2016, p.170) e, com base nesse 
"grupo central", podem-se identificar outros grupos periféricos de periódicos com menor produtividade. Cabe ressaltar que cada "cluster" ou grupo deve conter 1/3 do total de artigos relevantes (Rodrigues \& Vieira, 2016).

Por fim, a Lei de Zipf (1949), que permite ao pesquisador observar as frequências de ocorrência de palavraschave em um único ou em um grupo de textos científicos, pode, assim, observar tendências que indicam os assuntos dos documentos. De acordo com Rodrigues e Vieira (2016, p. 170), para Zipf "se forem listadas as palavras que ocorrem num texto em ordem decrescente de frequência, a posição de uma palavra na lista multiplicada por sua frequência é igual a uma constante".

Segundo Rodrigues e Vieira (2016), a Lei de Zipf pode ser expressa pela equação $r$ x $f=k$, em que a variável " $r$ " é a posição da palavra-chave, "f" é a frequência e " $k$ " é a constante. Percebe-se, de acordo com equação, a curva de Zipf, que, por sua vez, é divida em três zonas de distribuição, a saber:

[...] a Zona I - Informação trivial ou básica define os temas centrais da análise bibliométrica; a Zona II - Informação interessante se localiza entre as Zonas I e III e mostra ora os temas periféricos, ora a informação potencialmente inovadora - é aí que as transferências de tecnologia relacionadas aos novos temas devem ser consideradas; e a Zona III - Ruído tem como característica possuir conceitos ainda não emergentes, sendo impossível afirmar se eles serão emergentes ou se são apenas ruídos estatísticos (Rodrigues \& Vieira, 2016, p. 171)

Assim, com base na curva de Zipf e suas três zonas de distribuição, é possível compreender os temas centrais da análise bibliométrica e os temas periféricos, identificando potenciais inovações para o campo de estudo.

\subsection{Procedimentos metodológicos}

Esta pesquisa utilizou cinco bases de dados para a realização de buscas por periódicos que utilizam em suas pesquisas empíricas metodologias de análise de imagens. As bases selecionadas foram Scielo, Spell, Publicações em Turismo, Web of Science e Scopus, em razão de sua variedade de filtros e da indicação de pesquisadores da área do turismo. Entretanto, para além desses critérios primários, Scielo, Spell e Publicações em Turismo foram eleitas porque possuem ampla quantidade de artigos nos idiomas português e espanhol, além de disponibilizarem artigos completos. Web of Science e Scopus, por sua vez, foram utilizadas porque reúnem periódicos renomados no idioma inglês.

As palavras-chave utilizadas levaram em conta a experiência em pesquisas anteriores realizadas pelas autoras deste trabalho e buscas primárias nas bases escolhidas. Também foram realizados pré-testes, adotando termos relacionados com o tema de pesquisa, a fim de que pudesse se obter como resultado artigos que respondessem à questão problema e ao objetivo do trabalho. Assim, ao final desses testes, foram definidas as palavras-chave "análise da imagem", "fotografia", "turismo" e "imagem", sendo possível verificar as metodologias de análise da imagem mais recorrentes no campo do turismo. Os termos foram buscados em português, inglês e espanhol ${ }^{2}$. A busca nas bases pelas palavras-chave foi realizada com auxílio do operador booleano "and"3, de modo a cruzar os termos entre si, e de filtros que delimitaram o campo de pesquisa em turismo, bem como o recorte temporal de 2012 a 2017, para que se pudesse obter a produção mais atual. Cabe ressaltar que a relevância dos periódicos não foi um dos critérios filtros, pois seria um fator limitante para a pesquisa.

Para o filtro dos periódicos, utilizou-se o software de gestão de dados Mendeley. Assim, na etapa 1 da coleta de dados, foram recuperados 205 artigos, mas, excluídas as duplicatas, restaram 185. Na etapa 2, após avaliação por títulos e resumos, a fim de verificar se os documentos baseavam sua metodologia em análise de fotografias, foram recuperados 42 artigos. Foram desconsiderados artigos que utilizavam o termo imagem com o sentido de imaginário. Por fim, na etapa 3, restaram 40 artigos, pois não foram encontrados todos os artigos da etapa anterior completos e disponíveis.

\footnotetext{
2 Os termos utilizados nas buscas em inglês foram "image analysis", "photograph", "tourism" e "image"; em espanhol, "análisis de la imagen", "fotografia", "turismo" e "imagen".

${ }^{3}$ Exceto na base Publicações em Turismo, em que a busca pelas palavras-chave foi realizada com auxílio de vírgulas para separar os termos.
} 
Figura 1. Síntese dos procedimentos metodológicos adotados para a seleção do material analisado.

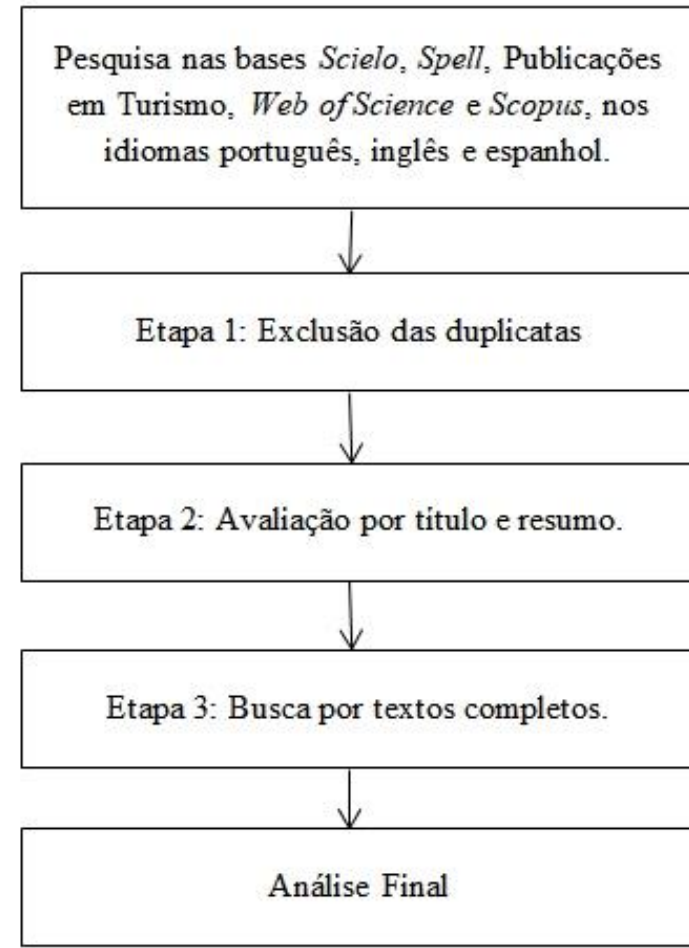

\section{Recuperados: \\ 205 artigos}

\section{Restaram: \\ 185 artigos}

\section{Restaram:}

42 artigos

\section{0 artigos}

Fonte: Adaptado de Silveira, et. al. (2011).

Embora a Leis de Lotka e Bradford indiquem a importância da avaliação do nível Qualis do periódico - no caso do Brasil -, o fator de impacto das revistas internacionais e a produtividade do autor, esses não foram critérios de seleção e descarte dos artigos, pois entende-se que o número de pesquisas em turismo que adotam tais metodologias e que foram encontradas nas bases pesquisadas ainda não é significativo como no caso das metodologias tradicionais (Bauman, Lourenço \& Lopes, 2017; Matteucci, 2013).

Cabe salientar que este artigo privilegiou a descrição das metodologias de análise da imagem encontradas nas pesquisas empíricas e a análise da evolução do uso dessas metodologias ao longo dos últimos cinco anos, indicando também as principais áreas do turismo que fazem uso da leitura de fotografias como método de pesquisa.

Optou-se pela construção deste artigo desse modo, pois, assim como aponta Chueke e Amatucci (2015), "as análises descritivas fazem parte do corpo de um artigo que adota a bibliometria como método" (p. 4). Além disso, os autores sinalizam a importância de relacionar essas análises "à evolução do campo e realizar prescrições para futuros pesquisadores" (p.4).

\section{RESULTADOS E DISCUSSÃO}

A Lei de Lotka aponta a necessidade de mapear os autores que possuem maior produção e, portanto, grande valor em um campo do conhecimento. No entanto, nesta pesquisa, esse dado não se mostrou relevante, pois foram mapeadas apenas duas repetições de autor, a saber, José Manoel Gonçalves Gândara, que aparece em três artigos: dois deles em parceria com Franciele Manosso, nos anos 2013 e 2016, em pesquisas que tratam, respectivamente, da análise de fotografias turísticas em redes sociais como Flickr e Instagram; e o terceiro trabalho do autor em parceria com a autora Cynthia Mello Ferrari (2015), em artigo sobre fotografias de viagens em Curitiba (PR).

Como abordado na metodologia, o presente estudo buscou analisar o modo como as metodologias de análise da imagem estão sendo utilizadas na pesquisa em turismo. A busca foi realizada em bases de dados 
nacionais e internacionais, e os resultados foram diversos, encontrando periódicos de todas as partes do mundo.

Assim como indica a Lei de Bradford, demonstrada na Tabela 1, os periódicos analisados foram dispostos em ordem decrescente, de acordo com a quantidade total de artigos produzidos. Os artigos foram somados e divididos por 3 para que se pudesse obter os três clusters, cada um contendo cerca de 1/3 dos periódicos relevantes para o campo das metodologias de análise da imagem.

De acordo com a Tabela 1, observa-se que no cluster central estão os periódicos mais produtivos em ordem decrescente por número de artigos publicados. Juntos, os 5 primeiros periódicos que aparecem na tabela 1 somam 40\% da produção encontrada nesta pesquisa, enquanto o cluster secundário possui 10 periódicos que contabilizam $32,50 \%$ da produção sobre metodologias de análise da imagem no recorte temporal de 2012 a 2017 . E o terceiro cluster, que apresenta 11 periódicos, possui $27,50 \%$ dos artigos produzidos no período analisado.

Assim, observa-se a aplicação da teoria de Bradford, pois há um grupo menor de periódicos - a saber, Annals of Tourism Research (4); Journal of Travel Research (3); Asia Pacific Journal of Tourism Research (3); Journal of Sustainable Tourism (3) e Tourism \& Management (3) - que é responsável por 40\% da produção científica encontrada em um período de 5 anos sobre o tema metodologias de análise da imagem. Além disso, de acordo com a Tabela 1, pode-se verificar que não houve uma evolução contínua do uso dessas metodologias de pesquisa em turismo. Entretanto, nota-se um aumento nos anos 2015 e 2016.

A Tabela 2 apresenta a frequência das palavras-chave mais utilizadas nos 40 artigos analisados. Foram identificadas 128 palavras-chave, entretanto, cumpre ressaltar que dois artigos não utilizaram esses termos de indexação. Os temas mais recorrentes nos trabalhos analisados são fotografia (17), imagem (12), turismo (12), destino turístico (8), metodologias visuais (6), análise de conteúdo (5) - um dos métodos utilizados nas análises de imagens - e turistas (3).

Segundo o que postula a Lei de Zipf, pode-se separar esse conjunto palavras em três zonas. A Zona I diz respeito às informações triviais ou básicas, definindo, assim, os temas centrais da análise bibliométrica. Nesse caso, observa-se que os temas centrais dessa análise são fotografia, imagem e turismo, isto é, os termos mais citados nas palavras-chave dos artigos analisados.

A Zona II - Informações interessantes, indica os temas periféricos que podem apresentar possibilidades de novas pesquisas e temas inovadores. Nesse caso, conforme demonstra a tabela 2, as informações periféricas dessa pesquisa são destino ou destinos turísticos, metodologias visuais, análise de conteúdo e turistas. Nota-se que, nessa pesquisa, as informações interessantes complementam as informações triviais e, portanto, aparecem nas discussões desse artigo.

Foram identificadas também 65 palavras-chave com apenas duas ou uma ocorrência. Assim, como postula a Lei de Zipf, nessa pesquisa considerou-se esse grupo de palavras como "Ruídos". De acordo com a teoria de Zipf, as palavras-chave que se repetiram apenas duas vezes ou que não se repetiram são termos que não possuem ainda conceitos ou relevância para essa pesquisa. 
Tabela 1 - Periódicos escolhidos para pesquisa

\begin{tabular}{|c|c|c|c|c|c|c|c|}
\hline \multirow[t]{2}{*}{ Revistas } & \multicolumn{6}{|c|}{ Ano } & \multirow[b]{2}{*}{ Soma } \\
\hline & 2012 & 2013 & 2014 & 2015 & 2016 & 2017 & \\
\hline \multicolumn{8}{|l|}{ Cluster central } \\
\hline Annals of Tourism Research & 2 & 0 & 0 & 1 & 1 & 0 & 4 \\
\hline Journal of Travel Research & 0 & 2 & 1 & 0 & 0 & 0 & 3 \\
\hline Asia Pacific Journal of Tourism Research & 0 & 0 & 0 & 1 & 1 & 1 & 3 \\
\hline Journal of Sustainable Tourism & 0 & 2 & 0 & 0 & 1 & 0 & 3 \\
\hline Tourism \& Management & 0 & 1 & 1 & 0 & 1 & 0 & 3 \\
\hline \multicolumn{8}{|l|}{ Cluster 2} \\
\hline Estudios y Perspectivas en Turismo & 1 & 0 & 0 & 0 & 1 & 0 & 2 \\
\hline Caderno Virtual de Turismo & 0 & 0 & 0 & 1 & 1 & 0 & 2 \\
\hline Revista Hospitalidade & 0 & 0 & 0 & 1 & 1 & 0 & 2 \\
\hline Iranian Studies & 0 & 0 & 0 & 0 & 0 & 1 & 1 \\
\hline Applied Geography & 0 & 0 & 0 & 1 & 0 & 0 & 1 \\
\hline $\begin{array}{l}\text { International Journal of Tourism Research and Hos- } \\
\text { pitality }\end{array}$ & 0 & 0 & 0 & 1 & 0 & 0 & 1 \\
\hline Leisure Studies & 0 & 0 & 0 & 1 & 0 & 0 & 1 \\
\hline Marketing \& Tourism Review & 0 & 0 & 0 & 0 & 1 & 0 & 1 \\
\hline Pampa & 1 & 0 & 0 & 0 & 0 & 0 & 1 \\
\hline Geographical Research & 1 & 0 & 0 & 0 & 0 & 0 & 1 \\
\hline \multicolumn{8}{|l|}{ Cluster 3} \\
\hline International Journal of Heritage Studies & 0 & 0 & 0 & 0 & 1 & 0 & 1 \\
\hline Tourism \& Management Studies & 0 & 0 & 0 & 0 & 1 & 0 & 1 \\
\hline The Sociological Review & 1 & 0 & 0 & 0 & 0 & 0 & 1 \\
\hline Revista Turismo em Análise & 0 & 0 & 0 & 0 & 0 & 1 & 1 \\
\hline $\begin{array}{l}\text { International Journal of Culture, Tourism and Hos- } \\
\text { pitality Research }\end{array}$ & 0 & 0 & 0 & 1 & 0 & 0 & 1 \\
\hline Turismo e Sociedade & 0 & 1 & 0 & 0 & 0 & 0 & 1 \\
\hline Current Issues in Tourism & 0 & 0 & 0 & 1 & 0 & 0 & 1 \\
\hline Tourism Management Perspectives & 0 & 0 & 1 & 0 & 0 & 0 & 1 \\
\hline The Australian Educational Researcher & 0 & 1 & 0 & 0 & 0 & 0 & 1 \\
\hline $\begin{array}{l}\text { Revista Brasileira de Pesquisa em Turismo } \\
\text { Outros }\end{array}$ & 0 & 0 & 1 & 0 & 0 & 0 & 1 \\
\hline $\begin{array}{l}\text { Seventh International Conference on Complex, In- } \\
\text { telligent, and Software Intensive Systems }\end{array}$ & 0 & 1 & 0 & 0 & 0 & 0 & 1 \\
\hline Total & 6 & 8 & 4 & 9 & 10 & 3 & 40 \\
\hline
\end{tabular}

Fonte: Elaboração própria (2018). Adaptado de Rodrigues \& Vieira (2016)

\begin{tabular}{ll} 
Tabela 2 -Densidade das Palavras-chave & \\
\hline Palavras-chave & Frequência \\
\hline Zona I - Informação trivial ou básica & 17 \\
Fotografia & 12 \\
Imagem & 12 \\
Turismo & \\
Zona II - Informação interessante & 8 \\
Destino(s) turístico(s) & 6 \\
Metodologias Visuais & 5 \\
Análise de Conteúdo & 3 \\
Turista(s) &
\end{tabular}

Fonte: Elaboração própria (2018).

A Tabela 3 apresenta os tipos de metodologias de análise da imagem utilizadas pelos autores. Observa-se que nos periódicos analisados destacam-se predominantemente o uso da análise de conteúdo (28\%) e da semiótica (26\%). Outras metodologias apareceram mais sutilmente, como é o caso da volunteer-employed photography (11\%), da antropologia visual/fotoetnografia (11\%), da foto elicitação (9\%), da Zaltman metaphor elicitation technique (ZMET) (2\%), e outras (13\%), entre as quais a iconografia. Sobre essas outras, os autores não utilizaram nenhuma metodologia de análise da imagem tradicional, apenas interpretaram as 
fotografias de modo qualitativo, de forma semelhante ao que se faz na Antropologia Visual. Entretanto, porque não há diário de fotografia e, em alguns casos, os dados foram coletados pela internet, não se pode classificar como tal.

Um dado relevante obtido na análise dos periódicos é que poucos deles utilizam metodologias únicas. Nem todos apresentaram de modo claro no texto o porquê de mesclarem vários métodos em uma só pesquisa, mas acredita-se que a combinação de métodos gere resultados mais seguros e aparentemente confiáveis ao leitor. Segundo Nika Balomenou e Brian Garrod (2014), há insegurança a respeito da utilização de métodos qualitativos, em razão da subjetividade. No entanto, é importante ressaltar que, em qualquer campo da pesquisa científica, e não somente no da pesquisa social, interpretação de dados implica subjetividade, e o mito da almejada neutralidade científica não se sustenta. Ao contrário, variáveis não precisam estar necessariamente isoladas para se atingir um resultado, na medida em que são justamente parte epistemológica do problema. Contudo, os autores sugerem que o pesquisador fique atento e crie um filtro que separe o lado pessoal do profissional.

Verificou-se em sete artigos a utilização da análise de conteúdo como metodologia única, seis utilizaram a semiótica, um fez uso da fotoetnografia, um utilizou a iconografia, e também apenas um, o novo método ZMET. No caso desses artigos, a combinação de métodos foi desconsiderada. Já os 24 artigos restantes utilizaram métodos combinados, o que indicou maior aprofundamento na análise dos materiais coletados. Em geral, os métodos de análise de imagem se mesclavam com entrevistas em profundidade ou pesquisas documentais e bibliográficas.

No caso das pesquisas multimétodos, isto é, que combinavam a análise quantitativa com o qualitativo, o resultado foi ainda mais proveitoso. Notou-se a combinação da metodologia análise de conteúdo com as entrevistas, além de semiótica atrelada aos testes quiquadrado.

Tabela 3 - Tipos de métodos utilizados

\begin{tabular}{|c|c|c|c|c|c|c|}
\hline \multirow{2}{*}{ Tipo de Método } & \multicolumn{6}{|c|}{ Ano } \\
\hline & 2012 & 2013 & 2014 & 2015 & 2016 & 2017 \\
\hline Análise de conteúdo & 2 & 3 & 2 & 1 & 3 & 2 \\
\hline Semiótica & 1 & 0 & 0 & 5 & 4 & 2 \\
\hline Antropologia Visual/Fotoetnografia & 1 & 1 & 0 & 1 & 2 & 0 \\
\hline VEP & 0 & 3 & 1 & 1 & 0 & 0 \\
\hline Foto Elicitação & 1 & 1 & 0 & 1 & 1 & 0 \\
\hline ZMET & 0 & 1 & 0 & 0 & 0 & 0 \\
\hline Outras metodologias de análise de imagens & 1 & 1 & 1 & 1 & 2 & 0 \\
\hline Total $^{1}$ & 6 & 10 & 4 & 10 & 12 & 4 \\
\hline
\end{tabular}

10 total fica maior que a quantidade de artigos porque, em várias pesquisas, é utilizada mais de uma metodologia

Fonte: Elaboração própria (2018)

A Tabela 4 refere-se aos campos do estudo em turismo em que foram empregadas metodologias de análise da imagem. Foram encontradas nos artigos tendências às seguintes áreas, entre outras: gestão e marketing de destinos turísticos, patrimônio, hospitalidade, antropologia do turismo.

O campo "gestão e marketing de destinos turísticos" concentrou o maior número de pesquisas. Nessa categoria, foram agrupadas pesquisas que buscavam identificar a imagem das destinações e como elas impactam o imaginário do turista, de modo a promover mudanças na gestão ou no marketing dos locais. Já na categoria patrimônio, foram selecionadas pesquisas que procuravam entender a relação entre o patrimônio histórico e cultural e o turismo.

$\mathrm{Na}$ categoria hospitalidade foram alocadas as pesquisas que se relacionavam com o estudo dos encontros entre hóspedes e anfitriões e que buscavam compreender a experiência turística. Em antropologia do turismo, estavam posicionados estudos que contemplavam comunidades ou aspectos socioculturais da atividade. "Outros campos do turismo" refere-se a pesquisas que não se posicionaram em somente uma área. 
Tabela 4 - Campos temáticos em que foram aplicadas metodologias visuais

\begin{tabular}{|c|c|c|c|c|c|c|}
\hline \multirow[t]{2}{*}{ Campo temático } & \multicolumn{6}{|c|}{ Ano } \\
\hline & 2012 & 2013 & 2014 & 2015 & 2016 & 2017 \\
\hline Gestão/marketing de destinos turísticos & 3 & 3 & 3 & 2 & 4 & 2 \\
\hline Patrimônio & 1 & 1 & 1 & 3 & 0 & 0 \\
\hline Hospitalidade & 0 & 0 & 0 & 0 & 3 & 0 \\
\hline Antropologia do turismo & 1 & 0 & 0 & 0 & 1 & 1 \\
\hline Outros campos do turismo & 2 & 4 & 0 & 4 & 2 & 0 \\
\hline Total & 6 & 8 & 4 & 9 & 10 & 3 \\
\hline
\end{tabular}

Fonte: Elaboração própria (2018)

\subsection{Discussão sobre metodologias de pesquisa: possibilidades metodológicas para pesquisa em Hospitali- dade}

Aquino (2017) se baseia na teoria de estudiosos como Walter Benjamin (1985) e David Harvey (2011) e, com base nesses autores, afirma que há na modernidade uma condição de instabilidade. Isto propicia o "desenvolvimento da fotografia como meio de descrever, analisar, catalogar e viabilizar a circulação de pequenos fragmentos do mundo" (AQUINO, 2017, p. 90). Desse modo, por meio dos "fragmentos do mundo" representados em uma fotografia, poder-se-ia responder questões relacionadas com qualquer área do conhecimento.

De acordo com Azevedo (2017, p. 1011) uma fotografia pode ser "uma representação da identidade de um lugar, contagiar emoções, simular/emular experiências e motivar a visita ao destino". Na contemporaneidade, sobretudo, após o advento dos smartphones com câmeras integradas, a fotografia demonstrou-se intimamente ligada ao turismo. Nesse contexto, reforça-se a importância do estudo da fotografia na atividade turística como sinalizado por Aquino (2017).

No campo do turismo, "tudo existe para terminar em uma foto" (Aquino, 2017, p. 90) e, portanto, o ato de fotografar passa a ser simbólico, significa o "estar lá". Segundo tal representação imagética, eternizada na forma de uma fotografia, o pesquisador pode recolher importantes informações sobre seu objeto de pesquisa.

Assim, com base nas análises realizadas na sessão anterior, nota-se que a fotografia como método de estudo, de 2012 a 2017, tem sido explorada de modo insuficiente em relação aos métodos convencionais. Em geral, a análise de imagem no turismo está relacionada ao campo de gestão e marketing de destinos. Essa tendência ocorre, pois, de acordo com Mello (2015, p. 490) a fotografia é considerada, na atualidade, um "suporte estratégico para os enunciadores midiáticos, governamentais e empresariais materializarem os destinos turísticos". Entretanto, os métodos que utilizam fotografias como fonte de informação turística podem e devem contribuir com outros campos da pesquisa em turismo, como o das ciências sociais e o da hospitalidade.

Camargo (2008) aponta que a pesquisa em hospitalidade se tem restringido a metodologias convencionais de pesquisa, como questionários de satisfação, observação direta, análise da oferta turística e entrevistas em profundidade. 0 autor aponta a semiótica como um dos caminhos para inovação na área, que torna possível analisar por meio de símbolos e códigos nuances subjetivas da hospitalidade no turismo. No entanto, como exposto anteriormente, direcionar a pesquisa de hospitalidade ao método da semiótica não é o bastante. Há inúmeras possibilidades de análises nos mais diversos espaços ao se adotarem outras metodologias de análises visuais, tanto quantitativas quanto qualitativas.

Pode-se aplicar aos estudos de hospitalidade a análise de conteúdo e, assim, de modo quantitativo, analisar fotografias de instituições ou turistas, de modo a verificar quais são os símbolos de hospitalidade do destino turístico. E, para além disso, levar em conta também conteúdo de sites de instituições, comentários de páginas nas redes sociais, a fim de verificar o modo como os turistas foram recebidos por um destino turístico ou um atrativo. A possibilidade oferecida pela análise de conteúdo parece simples, mas devido à fluidez das visitas turísticas, os detalhes minuciosos presentes em comentários despretensiosos em sites de viagens, por exemplo, tornam-se difíceis de coletar. 
No entanto, dentre todas as metodologias, a fotoetnografia com a combinação de outros métodos e técnicas da Antropologia promete oferecer uma contribuição mais consistente para o campo da hospitalidade. A fotoetnografia, se combinada à técnica do volunteer-employed photography e aos diários de fotografia, pode captar a subjetividade e as relações de hospitalidade nos espaços. Por meio da análise de imagens aliada aos registros do diário, seria possível obter informações a respeito do olhar dos turistas e contrapor a interpretação do pesquisador a escritas do entrevistado. Além disso, adotando métodos etnográficos, podese complementar a pesquisa com entrevistas em profundidade.

Evidentemente, a escolha dos métodos deverá ocorrer de acordo com o problema da pesquisa, o objeto de estudo, os sujeitos envolvidos, as condições do campo e os objetivos a serem alcançados. Todavia, esses são alguns caminhos que apontam possibilidades de ampliação do universo metodológico da pesquisa em hospitalidade.

Outra possibilidade e tendência verificada na análise dos artigos foi o uso das redes sociais como uma das fontes de coleta de imagens fotográficas para a realização de pesquisas que utilizem análise de imagens como metodologia. Notou-se que uma pequena parcela dos autores optou por coletar suas fotos nas redes sociais. Mello (2015) acredita que esse é um fenômeno que tende a crescer. Para a autora, o mais recente resultado da união entre turismo e fotografia são as fotografias publicadas em mídias sociais como Facebook, Instagram e Flickr, ou em sites de recomendação como o Tripadvisor.

No entanto, a utilização de fotos pessoais recolhidas em redes sociais gera também um debate ético. Como salientado anteriormente, é necessário tomar as medidas devidas para assegurar a integridade do pesquisado. Assim, como indica Diniz (2008), o pesquisador deve ser cuidadoso ao analisar expressões, vestes e aparência dos indivíduos que aparecem nas imagens e, sobretudo, pedir autorização por meio dos termos de consentimento livre e esclarecido ao pesquisado para a publicação, se necessário, da foto em um trabalho acadêmico.

Contudo há inúmeras maneiras pouco exploradas para estudar elementos do turismo adotando a imagem fotográfica, como demonstram os resultados de pesquisa descritos anteriormente. Entretanto, de acordo Siqueira, Manosso \& Massukado-Nakatani (2014), analisar uma imagem, independente da metodologia escolhida, é um processo complexo que oferece ao pesquisador diferentes perspectivas e promove novos e mais profundos questionamentos, indicando, assim, a relevância e o poder do uso das metodologias de análise da imagem ao se estudar fotografias em turismo. Esse é um dos motivos pelos quais foi criado o L'Image (Laboratório de Metodologias de Análise da Imagem) para estudos em Turismo e Cultura, aprovado em Edital Universal do CNPq e que se encontra em pleno desenvolvimento. 0 presente artigo faz parte dos estudos que colaboram para o aprofundamento desse campo do saber.

\section{CONCLUSÕES}

A fotografia oferece múltiplas possibilidades à pesquisa científica em turismo que estão para além da mera utilização dessas imagens fotográficas como ilustração de textos. Entretanto, em muitos casos, o pesquisador desconhece as inúmeras metodologias de análise visuais que podem proporcionar a leitura adequada desse tipo de material. Nesse sentido, este artigo buscou sistematizar as principais metodologias utilizadas em pesquisas empíricas nos últimos cinco anos, a fim de apresentar aos pesquisadores em turismo novas possibilidades.

As metodologias visuais mostram-se eficientes, para captar elementos subjetivos da atividade turística, e vantajosas, na medida em que podem ser alinhadas a outros métodos de pesquisa qualitativos e/ou quantitativos. No entanto, como observado, o pesquisador precisa se atentar quanto aos cuidados éticos que devem ser adotados no trabalho com imagens, em especial, com fotografias.

Nas sessões anteriores, observou-se que as pesquisas em turismo nacionais que utilizam metodologias de análise da imagem ainda são incipientes, concentrando-se, em sua maioria, no campo de gestão de destinos e marketing, restrito a investigar sobre a criação de novos imaginários turísticos com vistas à captação de turistas. 
Em contrapartida, estudos internacionais mostraram-se promissores no uso de técnicas como VEP e ZMET para coleta de fotografias, bem como no uso eficiente da metodologia de análise de conteúdo para gerar resultados práticos, com base em imagens de sites de relacionamento, como o Instagram e o Flickr.

Foi encontrada em metade dos artigos analisados a utilização de metodologias de análise de conteúdo e semiótica, que para o campo podem ser consideradas tradicionais. Notou-se que o uso significativo da fotoetnografia vem-se consolidando com o passar dos anos. Isso também indica novas possibilidades de uso dos métodos da antropologia visual.

Em 30\% dos periódicos analisados, os autores não identificam a metodologia utilizada, limitando-se a interpretar livremente as imagens - o que dificulta a replicação do método em outras pesquisas.

É preciso ressalvar que esta pesquisa apresentou recorte temporal e está circunscrita a um curto período de produção (2012 a 2017). Também foram analisados somente periódicos, desconsiderando livros, anais de eventos, entre outras publicações. Almeja-se que, em futuro próximo, seja possível ampliá-la, levando em consideração produções diversas e expandindo seu recorte temporal, a fim de que se mapeiem outros usos de metodologias de análise de imagem no turismo.

Diante do exposto, espera-se que este estudo estimule inovações no campo da pesquisa, especialmente no Brasil, apontando caminhos metodológicos, indicando possibilidades de diversificação da investigação científica para a área e auxiliando pesquisadores a adotarem tais métodos em seus trabalhos, atribuindoIhes, assim, relevância acadêmica.

\section{REFERÊNCIAS}

Achutti, L. E. R. (1997). Fotoetnografia: um estudo de antropologia visual sobre cotidiano, lixo e trabalho. Porto Alegre: Tomo Editorial.

Azevedo, A. (2017). Significados latentes na fotografia em turismo: o caso do turismo negro na Costa Morte (Galiza). PASOS. Revista de Turismo y Patrimonio Cultural [en linea], 15(4), 1001-1015. https://doi.org/10.25145/j.pasos.2017.15.067

Balomenou, N., \& Garrod, B. (2014). Using volunteer-employed photography to inform tourism planning decisions: A study of St David's Peninsula, Wales. Tourism Management, 44, 126-139. https://doi.org/10.1016/j.tourman.2014.02.015

Barthes, R. (1984). A câmara clara: nota sobre a fotografia. Rio de Janeiro: Editora Nova Fronteira.

Baumann, F.; Lourenço, P. \& Lopes, M. (2017). Imagem projectada e percebida de um destino através da fotografia digital. A rede Instagram como nova resposta para a recolha de dados: 0 caso de estudo de Lisboa. Revista Turismo \& Desenvolvimento, 27(28), 1409-1422.

Bergesio, L, Montial, J. \& Scalone, L. (2012). Territorio imaginado: El caso de la Quebrada de Humahuaca. Pampas, 1(8), 111-136. https://doi.org/10.14409/pampa.v1i8.3218

Cahyanto, I., Pennington-gray, L. \& Thapa, B. (2013). Tourist-resident interfaces: using reflexive photography to develop responsible rural tourism in Indonesia, Journal of Sustainable Tourism, 21(5), 732-749. https://doi.org/10.1080/09669582.2012.709860

Camargo, L. O. de L. (2008). A pesquisa em hospitalidade. Revista Hospitalidade, 5 (2), 15-51.

Campos, S. M. C. T. L. (1996). A imagem como método de pesquisa antropológica: um ensaio de Antropologia Visual. Revista do Museu de Arqueologia e Etnologia, São Paulo, 6, 275-286. https://doi.org/10.11606/issn.2448-1750.revmae.1996.109274

Cavedon, N. R. (2005). Fotoetnografia: a união da fotografia com a etnografia no descortinamento dos não ditos organizacionais. Organizações \& Sociedade [online], 12(35), 13-27. https://doi.org/10.1590/S1984$\underline{92302005000400001}$

Chueke, G. V. \& Amatucci, M. (2015). O que é bibliometria? Uma introdução ao Fórum. Internext. 10(2), 1-5. https://doi.org/10.18568/1980-4865.1021-5

Coghlan, A.; Prideaux, B. (2008) Encounters with Wildlife in Cairns, Australia: Where, What, Who...?. Journal of Ecotourism, vol.7, n. 1, p.68-76. https://doi.org/10.2167/joe174.0 
Diniz, D. (2008). Ética na pesquisa em ciências humanas - novos desafios. Ciência \& Saúde Coletiva. 13(2), 417 - 426. https://doi.org/10.1590/S1413-81232008000200017

Donaire, J. A., \& Galí, N. (2011). La imagen turística de Barcelona en la comunidad de flickr. Cuadernos De Turismo, (27), 291-303.

Edwards, E. (2016). Rastreando Fotografia. A experiência da imagem na Antropologia. São Paulo: Terceiro Nome.

Ferrari, C. M. M. \& Gândara, J. M. (2015). Fotografias de viagens: replicando cenas da viagem perfeita em Curitiba/PR, Caderno Virtual de Turismo, 15(2), 112-130.

Foster, L. (2017). Picture ahead: a Kodak e a construção do turista-fotógrafo. Significação: Revista de Cultura Audiovisual, 44(48), 230-237. https://doi.org/10.11606/issn.2316-7114.sig.2017.137654

Gastal, S. (2005). Turismo, Imagens e Imaginário. São Paulo: Aleph.

Joly, M. Introdução à análise da imagem. M. Appenzeller, Trad. Campinas, SP: Papirus 2012, 14a ed.

Khoo-Lattimore, C. \& Prideaux B. (2013). ZMET: a psychological approach to understanding unsustainable tourism mobility. Journal of Sustainable Tourism, 21(7), 1036-1048, https://doi.org/10.1080/09669582.2013.815765

Manosso, F.C., Bizinelli, C. \& Gândara, J. M. (2013). A Imagem da Cidade em Fotografias Online: Estudo de Caso do Site Flickr sobre Curitiba (Paraná, Brasil). Turismo \& Sociedade. 6(4), 835-860. https://doi.org/10.5380/tes.v6i4.31747

Manosso, F. C. \& Gândara, J. M. (2016). La materialización de la experiencia en el espacio urbano-turístico a través de las fotografías online: Un Análisis en la Red Social Instagram. Estudios y perspectivas en turismo, 25(3), 279-303.

Martins, H. (2016). Para uma antropologia visual do turismo: 0 uso crítico de metodologias e materiais visuais. Pasos: Revista de Turismo y Patrimonio Cultural, 14(2), 527-541. https://doi.org/10.25145/j.pasos.2016.14.034

Matteucci, X. (2013). Photo elicitation: Exploring tourist experiences with researcher-found images. Tourism Management, 35, 190-197. https://doi.org/10.1016/i.tourman.2012.07.002

Megehee, C. M. \& Woodside, A. G. (2010). Creating visual narrative art for decoding stories that consumers and brands tell. Psychology \& Marketing, 27(6), 603-622. https://doi.org/10.1002/mar.20347

Meira, J.; Zucco, F. \& Dos Santos, T. (2017). Imagem Cognitiva e Imagem Afetiva: Um Estudo do Destino Blumenau, SC, Brasil. Revista Turismo em Análise, 28, 134. https://doi.org/10.11606/issn.1984 4867.v28i1p134-148

Mello, C. M. (2015). 0 modelo semiótico de análise e leitura sensorial de fotografias turísticas. Revista Hospitalidade, 12(1), 488-514.

Moretti, S. L. A.; Bertoli, B. J.; Zucco, F. D. (2016). A imagem de Blumenau no Instagram: um estudo sobre destino turístico em redes sociais usando equações estruturais. Caderno Virtual de Turismo, 16 (1), 126 140. http://dx.doi.org/10.18472/cvt.16n1.2016.1045.

Pérez,, X. P. (2012). El turismo indígena Guna (Panamá): Imaginarios y regímenes de mentira de las guías turísticas internacionales. Estudios Y Perspectivas En Turismo, 21, 945-962.

Prasad, B. D. (2008). Content analysis: A method in social science research. In: Lal Das, D.K \& Bhaskaran, V (eds.). Research methods for Social Work. New Delhi: Rawat.

Rial, C. (2014). Antropologia Visual: Perspectivas de Ensino e Pesquisa. 1. Brasília: Associação Brasileira de Antropologia, v. 1, 35-50.

Rodrigues, C. \& Godoy Viera, A. (2016). Estudos bibliométricos sobre a produção científica da temática Tecnologias de Informação e Comunicação em bibliotecas. CID: Revista de Ciência da Informação e Documentação, 7(1), p. 167-180. https://doi.org/10.11606/issn.2178-2075.v7i1p167-180

Barthes, R. A câmara clara: nota sobre fotografia. Tradução de Julio Castañon Guimarães. Rio Janeiro: Nova Fronteira, 1984

Salvagni, J. \& Silveira, M. A. N. (2013). Discursos Imagéticos: a fotografia como método da pesquisa social. Anais Eletrônicos do II Encontro História, Imagem e Cultura Visual. Porto Alegre. 1-8. 
Santos, P. M. (2016) Crossed gazes over an old city: photography and the 'Experientiation' of a heritage place. International Journal of Heritage Studies, $131-144$. https://doi.org/10.1080/13527258.2015.1108925

Silveira, P.S, Martins, L. F., Soares, R. G., Gomide, H. P. \& Ronzani, T. M. (2011). Revisão sistemática da literatura sobre estigma social e alcoolismo. Estudos de Psicologia, 16(2), 131-138. https://doi.org/10.1590/S1413-294X2011000200003

Siqueira, C. F.; Manosso, F. C. \& Massukado-Nakatani, M. S. (2014). O destino turístico representado por fotografias: analisando a caracterização de imagens. TURyDES, Turismo y Desarrollo Local, 7(16).

Stepchenkova, S. \& Zhan, F.Z. (2013) Visual Destination Image of Peru: Comparative Content Analysis of DMO and User-Generated Photography. Tourism Management, 36, 590-601. https://doi.org/10.1016/j.tourman.2012.08.006

Sontag, S. (2004). Sobre fotografia. São Paulo: Companhia das Letras.

Urry, J. (2001). O olhar do turista: lazer e viagens nas sociedades contemporâneas. São Paulo: Studio Nobel, SESC.

Urry, J.; Crashow, C. (2001). Tourism and the photographic eye. In: Rojek, C, Urry, J. (orgs), Touring cultures: transformation of travel and theory. London: Routledge.

Thurlow, C.; Jaworski, A. (2002). Banal globalization? Embodied actions and mediated practices in tourists online photo-sharing. In: Manovich, Lev. (2002) Digital Discourse Language in the New Media. Editora: Mit Press.

\section{Informações sobre os autores}

\section{Karla Estelita Godoy}

Professora Associada do Departamento de Turismo da Universidade Federal Fluminense, Vice-coordenadora do Programa de Pós-graduação Stricto Sensu em Turismo (PPGTUR - UFF) e Coordenadora do Grupo de Pesquisa Turismo, Cultura e Sociedade (T-Cult - UFF) e do Laboratório de Metodologias de Análise da Imagem (L'Image). Doutora em Políticas Públicas e Formação Humana pela Universidade do Estado do Rio de Janeiro (PPFH/UERJ) com Pós-doutorado no Programa de Pós-graduação em Antropologia da Universidade Federal Fluminense (PPGA/UFF).

Contribuições: Concepção do tema da pesquisa e do referencial teórico; orientação à pesquisa científica e metodológica; supervisão da coleta e interpretação de dados; redação e revisão textual e crítica do artigo científico; discussão dos resultados.

E-mail: karlagodoy@id.uff.br

ORCID: https://orcid.org/0000-0001-6753-5999

\section{lasmim da Silva Leite}

Mestranda em Turismo pelo Programa de Pós-Graduação Stricto Sensu em Turismo da Universidade Federal Fluminense (PPGTUR-UFF) e pesquisadora do Grupo de Pesquisa Turismo Cultura e Sociedade (T-Cult - UFF) e do Laboratório de Metodologias de Análise da Imagem (L'Image).

Contribuições: Formulação do tema e levantamento do referencial teórico; coleta e interpretação dos dados; redação e revisão crítica do artigo científico; discussão dos resultados.

E-mail: iasmimleite@id.uff.br

ORCID: https://orcid.org/0000-0002-7279-4300 